Dhaka Univ. J. Biol. Sci. 28(1): 9-20, 2019 (January)

\title{
EXPLORING PSYCHOLOGICAL CORRELATES OF PEERS AND FATHERS OF DRUG ADDICT ADOLESCENTS
}

\author{
Farjana BeGUM* AND SheikH IQbal MahmoOd \\ Department of Psychology, University of Dhaka, Dhaka-1000, Bangladesh
}

Key words: Peers, Fathers, Drug addict adolescent

\begin{abstract}
Drug dependency is clearly a problem for almost every country and Bangladesh is no exception. As the parents and peers are the closest persons of an adolescent whether addict or non-addict, so the present study was conducted with the following objectives: (a) To explore the peer relationship of the drug addict adolescents, (b) to investigate the parenting style of the fathers of the drug users and (c) to find the economic status of adolescent drug users. 60 male drug addict adolescents from different areas of Dhaka city were selected following snow ball technique. For the assessment of peer relation a scale drug and alcohol use-High risk behavior by Church (1994) was translated into Bangla and for assessing parenting style of the fathers of adolescents drug addicts Parental Acceptance/Rejection Questionnaire Child (PARQ), Short version of Rohner (2004b) was translated into Bangla and were used. For the analysis of the obtained data frequency count and percentage of responses made by the drug addict adolescent about their peers and fathers were calculated. The results show that the adolescent drug addict has very close relation with their peer as the type of drugs, frequency of taking drug and even factors determining their being drug addict are almost same. Results further show that parenting style of the fathers of the drug addict adolescent is rejective. Most of the adolescent get coldness or lack of affection, hostility or aggression, indifference or neglect, undifferentiated rejection but little warmth from their fathers. Finally, addiction is found to spread over access all economic status from almost lowest to highest in the present study.
\end{abstract}

\section{Introduction}

Substance abuse is a global phenomenon, becoming a burning issue in almost every country. It affects physical and mental health and lives of individuals including families, the legal systems, health care, and the work place. Problems of substance dependence produce dramatic costs to all societies in terms of loss of productivity, shortness of life expectancy, transmission of infectious diseases, family and social disorder, crime and excessive utilization of health care ${ }^{(1-4)}$.

*Author for correspondence: <fb.jharna13psy@yahoo.com>. 
Drug dependency is not a single incident, generally a developmental process. A person must have either positive or negative or both attitude towards the substance, then starts taking drug in an abnormal pattern like heavy and frequent use and finally become dependent on it. It is vital for both theoretical and applied that the researchers strive to understand the processes underlying the development of substance dependence.

Addiction is a primary, chronic, neurobiological disease with genetic, psychosocial, and environmental factors influencing its development and manifestations ${ }^{(5)}$. Addiction is generally considered to be a condition of psychological dependence with or without accompanying physical dependence. A drug user can be addicted even though there are no withdrawal symptoms. Addiction is the repetitive, compulsive use of a drug despite negative consequence to the user(6).

Peer group is a term commonly used by psychologists to describe people of a similar age, often when talking about adolescents. There is peer pressure in different ages and different places. Peer pressure or influence places a major role in drug abuse. Peer influences are also important in promoting alcohol and marijuana use ${ }^{(7)}$. And many people start taking drugs under peer pressure because their friends use drugs or they are forced to take it in fear of losing their friendship. Peers are crucial for adolescent's development because development needs to be in context which mainly means family and peers ${ }^{(8)}$. Adolescents who describe their family lives as troubled and who feel alienated from their families at the age of seven are more frequent users and abusers of drugs in adolescence ${ }^{(8)}$. This along with a lack of adult supervision, marriage problems and physical and sexual abuse are all positively correlated with substance abuse ${ }^{(8)}$. When a parent is addicted to alcohol or drugs, the entire family set up around the addict and their addiction. Children of drinking parents are more likely to associate with peers who have tried alcohol at ages 10 to 11, which increases the risk for alcohol use and misuse by the child.

Most parents believe that peer pressure is the primary reason teens use drugs, and two third of adolescents cite peer pressure as a reason. Having friends who smoke or drink has an influence on the adolescents, but peer pressure does not operate in a vacuum. In the majority of studies that simultaneously examined the influence of parents and peers on adolescents substance use, it was found that peers had a greater influence than parents ${ }^{(9)}$. Lack of parental affection, concern, involvement, conventional role modeling and guidance appear to be central factors in the family's influence on adolescent substance use ${ }^{(10)}$ and low levels of parental monitoring are associated with adolescents participation in substance use and drug trafficking ${ }^{(11)}$.Literatures have successfully recognized family risk factors for adolescent in drug abuse that include rejection by parents, parental and sibling substance use, divorce in family and conflict in family(12-13).Drug abusers tend to report a meaningfully poorer relationship with their parents compared to non-drug abuser(14). Some studies support the hypothesis that 
behavior like smoking, drinking, drug use and physical inactivity is more frequent among adolescents with a low economic family(15).

Nowadays number of adolescent drug users in Bangladesh is increasing at a very high rate. It is true that attempts are being made by different organization to reduce the problem but those are not enough to cope with the problem. As a number of research studies indicate that parent/fathers and peers have some role in adolescent drug abuse. So in the present study an attempt was made to understand the peer relation of the drug addict adolescent and the parenting style of their fathers. It was thought that in order to reduce the problem of adolescent drug abuse we should try to understand not only the abuser but also the individuals close to him. By focusing not only on the adolescent drug abuse but also on the person who may help to chalk effective programs for prevention and reducing the problem of drug addiction as the target population will be adolescent drug addiction as well as their peers and fathers.

The specific objectives of the present study were: (i) To explore the peer relationship of the drug addict adolescents, (ii) to investigate parenting style of the fathers of the adolescent drug users and (iii) to find the economic status of adolescent drug users.

\section{Materials and Methods}

The participants of the present study comprised of a total number of 60 drug addict adolescents. All of them were male. The age of the participants ranged from 15 - 18 years, the mean age was 16.5 years. Their educational levels were from illiterate to H.S.C. On the basis of the monthly income they were divided into three groups. The first was the upper economic class, having a family income of more than Tk. 55,000 per month. The second group belonged to the middle economic class, having a family income of Tk. 25,000 to 50,000 and the third group was derived from the lower economic class, whose income were less than Tk. 20,000 per month. The participants were selected from different areas of Dhaka city. Willingness of participants, drug addiction and males are the following criteria of selection of the participants were used through snow ball technique.

To collect the data, the present study used the following instruments. Drug and alcohol use - High risk behavior assessment scale: The Bangla version translated by Mahmood and Afrose ${ }^{(16)}$ and the original drug and alcohol use - High risk behavior assessment scale developed by Church ${ }^{(17)}$. This compendium of assessment tool is a publication of the national Centre for Injury Prevention and Control of the Centers for Disease Control and Prevention, of USA. This scale contains 5 items. The scale was applied on Asian American Students and their age ranged 8 - 18 years.

The purpose of the present study was to measure the role of peer on adolescent drug users in Bangladesh, but the English version of the drug and alcohol use - High risk behavior assessment scale was not suitable for the Bangladeshi drug abuse adolescents. 
Therefore the original English questionnaire of drug and alcohol use - High risk behavior assessment scale was translated into Bangla and used in the present study. At first each of the original scale was translated into Bangla by the researcher and corrected by the supervisor. Then the Bangla items were given to two English and Bangla language experts. They translated the Bangla items into English. Then synthesis of both version of the scale was done by the supervisor.

Reliability of the scale was measured by using Test-Retest method. To find out whether the translation was appropriate, a sample of 20 drug abuse adolescents who were in the age range of 15 to 18 years were selected from different areas of Dhaka city. Bangla version of the scale was administered upon the participants. Before administering the scale necessary rapport was built and the verbal consent of the respondents was taken. The respondents when approached for the first time were not informed that they would be given the same questionnaire again for retest. The same questionnaire was administered to the same group of participants, after an interval of one week. The Pearson- Product moment coloration $(r)$ between these two sets of score was computed and correlation was 0.57 which was significant at .05 level.

Parental Acceptance/Rejection Questionnaire-Child (PARQ): The Bangla version translated by Fatema and Afrose ${ }^{(18)}$ parental Acceptance/Rejection Questionnaire-Child (PARQ) originally developed by Rohner(19) is a self-report instrument designed to measure individuals' perceptions of parental acceptance-rejection. Bangla version of the PARQ consists of four scales: (1) Warmth/affection, (2) hostility/aggression, (3) indifference/neglect, and (4) undifferentiated rejection. The Bangla version contains 24 items. The correlation ranged from 0.90 to 0.88 and the test-retest reliability (r) of the PARQ was warmth/affection 0.90, hostility/aggression 0.73, indifference/neglect 0.76, undifferentiated/rejection $0.88(\mathrm{~N}=30)$. The purpose of the present research was to measure the role of parents on adolescent drug users of Bangladesh.

For conducting of the present study the cross sectional survey design was followed. The data were collected through interview. At first researcher asked some of his friends that weather they know any drug addict adolescent? Then some of his friends told that they knew some adolescent who take drug. Then researcher collected the address of drug addict adolescent from them and contacted with the drug addict adolescent. Firstly researcher introduces himself with the addicted adolescent and explained the objectives of the study. At first they did not agree to cooperate with the researcher but when the researcher assured confidentiality of their answer and it would be used in the study then they agreed to cooperate with the researcher. The respondents were instructed to read the items of the scales attentively and express their opinions by giving tick marks on corresponding boxes. They were also requested not to omit any item in the scales and they were encouraged to answer all the items by telling that there is no right or wrong answer to any items. However, in case of illiterate participant each item was presented 
one by one and their responses were recorded. It took around 20 minutes to complete the response for each respondent. They were warmly thanked after the data had collected.

\section{Results and Discussion}

To compute the result of the study the data were examined and coded extend into compute and analyzed with SPSS. The objectives of the present study were: (a) To explore the peer relationship of the drug addict adolescents, (b) to investigate the parenting style of the fathers of the drug users and (c) to find the economic status of adolescent drug users.

In order to explore if there is any involvement of peer in adolescent drug user, the data were collected by using drug and alcohol use - High risk behavior assessment scale. Here frequency count and percentage of responses given by the participants were calculated.

Table 1. Frequency count and percentage of peers using drugs.

Have your friends tried drugs or alcohol?

\begin{tabular}{lcc}
\hline Answer & No. of participants & Percentage \\
\hline Yes & 45 & 75 \\
No & 15 & 25 \\
\hline
\end{tabular}

Table 1 shows that $45(75 \%)$ adolescents reported that their friends took drugs or alcohol and the remaining $15(25 \%)$ of the drug addict adolescent told friends did not take drug or alcohol. When the participants were asked "Why do you think others try drugs and alcohol?" From the reports of participants some determinants are found.

The study reveals that $71.67 \%$ of the respondents mentioned that their friends took drug out of curiosity. $75 \%$ mentioned peer pressure played an important role for their friend's drug taking. $65 \%$ took drug for celebrating special occasion. $25 \%$ pointed that they took drug for the influence of media. 55\% reported about family history of drug use. $33.33 \%$ mention about family disorganization. $41.67 \%$ thought that their friends took drug for substance availability.

Table 3 shows that $66.67 \%$ participants took drugs because of curiosity and peer pressure. $58.33 \%$ of participants reported that they took drug for celebrating special occasion. $23.33 \%$ believed that media played an important role for their substance dependency. $50 \%$ and $41.67 \%$ of participants mentioned about family history of drug use and about family disorganization.

It was found that $41.67 \%$ of the participants reported that their friends took drug regularly, $50 \%$ occasionally and $8.33 \%$ of their friends took drug rarely. 
Table shows that $45 \%$ of the participants reported that they took drug and alcohol regularly, $45 \%$ occasionally and $10 \%$ respondents took drug rarely.

Table 2. Some determinants of drug used by peers of drug addicts.

\begin{tabular}{|c|c|c|c|}
\hline Category & Content & o. of respondents & $\%$ \\
\hline Curiosity & Exploring the experience of drug & 43 & 71.67 \\
\hline Peer pressure & $\begin{array}{l}\text { Dependent friends of peers of practicing } \\
\text { partner influenced and pressurized for substance }\end{array}$ & ce & 75 \\
\hline $\begin{array}{l}\text { Celebrate special } \\
\text { occasion }\end{array}$ & $\begin{array}{l}\text { To celebrate } 31^{\text {st }} \text { night, picnic, } 21^{\text {st }} \text { February, } \\
\text { birthday party }\end{array}$ & 39 & 65 \\
\hline Media & $\begin{array}{l}\text { Model's behavior such as stage program, } \\
\text { actor in TV drama, films, speech delivery } \\
\text { composed songs and poems }\end{array}$ & 15 & 25 \\
\hline $\begin{array}{l}\text { Family history of } \\
\text { drug use }\end{array}$ & Alcoholic father, uncle, cousin & 33 & 55 \\
\hline Family & Conflicting parental relationship & 20 & 33.33 \\
\hline Disorganization & $\begin{array}{l}\text { Authoritarian parenting style, } \\
\text { parental divorce }\end{array}$ & & \\
\hline Drug availability & $\begin{array}{l}\text { Easy availability of drug and drug } \\
\text { abuser take drugs openly }\end{array}$ & 25 & 41.67 \\
\hline
\end{tabular}

Table 3. Some determinants of drug use by the participants.

\begin{tabular}{lll}
\hline Category & No. of respondents & $(\%)$ \\
\hline Curiosity & 40 & 66.67 \\
Peer pressure & 40 & 66.67 \\
$\begin{array}{l}\text { Celebrate special } \\
\text { occasion }\end{array}$ & 35 & 58.33 \\
Media & 14 & \\
Family history of & 30 & 23.33 \\
drug use & & 50 \\
$\begin{array}{l}\text { Family } \\
\text { disorganization }\end{array}$ & 25 & \\
Drug availability & 26 & 41.67 \\
\hline
\end{tabular}

Table 6 shows that $36(80 \%)$ of the respondents perceived parental coldness and 9 (20\%) perceived parental warmth, $52(91.22 \%)$ perceived parental hostility and $5(8.77 \%)$ did not perceive parental hostility. $41(74.54 \%)$ perceived parental neglect and the 
remaining $14(25.45 \%)$ did not perceive parental neglect. 39 (71\%) perceived parental undifferentiated rejection and $16(29 \%)$ did not perceived undifferentiated rejection. On the other hand, $48(80 \%)$ of the respondents perceived rejection and only $12(20 \%)$ of the respondents did not perceive parental rejection.

Table 4. Rate of drug taken by peers of the participants.

How often?

\begin{tabular}{lcc}
\hline Rate of drug taking & Respondents & Percentage \\
\hline Rarely (1 - 3 years) & 5 & 8.33 \\
Occasionally (1 - 2 month) & 30 & 50 \\
Regularly (daily or 1 - 2 week) & 25 & 41.67 \\
\hline
\end{tabular}

Table 5. Rate of drug taken by the participants.

How often?

\begin{tabular}{lcc}
\hline Rate of drug taking & Respondents & Percentage \\
\hline Rarely (1 - 3 years) & 6 & 10 \\
Occasionally (1 - 2 month) & 27 & 45 \\
Regularly (daily or 1 - 2 week) & 27 & 45 \\
\hline
\end{tabular}

Table 6. Frequency count and percentage of respondents below and above mid-point.

\begin{tabular}{lccccc}
\hline Variables & $\begin{array}{c}\text { Midpoint } \\
\text { above midpoint }\end{array}$ & $\begin{array}{c}\text { No. of respondents } \\
\text { below midpoint }\end{array}$ & No. of respondents & (\%) \\
\hline Warmth/Affection & 20 & 9 & 20 & 36 & 80 \\
Hostility/Aggression & 15 & 52 & 91.22 & 5 & 8.77 \\
Indifference/Neglect & 15 & 41 & 74.54 & 14 & 25.45 \\
Undifferentiated/Rejection & 10 & 39 & 71 & 16 & 29 \\
Total Rejection & 60 & 48 & 80 & 12 & 20 \\
\hline
\end{tabular}

Table 7. Participant's distribution of different economic class.

\begin{tabular}{lcc}
\hline Family monthly income & No. of participants & Percentage \\
\hline Low $(1,500 / 20,000)$ & 31 & 51.65 \\
Middle $(25,000 /-50,000 /)$ & 12 & 19.99 \\
High $(55,000 /-1,00,000)$ & 17 & 28.34 \\
\hline
\end{tabular}


Table shows that highest number of drug addict participants $51.65 \%$ belong to $1,500 /$ 20,000 /and next highest number of respondents $28.34 \%$ belong to $55,000 /-1,00,000 \%$

The objectives of the present study were: (a) To explore the peer relationship of the drug addict adolescents, (b) to investigate of the parenting style of the fathers of the drug users and (c) to find the economic status of adolescent drug users. Following to the first objective it was found that $75 \%$ of the drug addict adolescents reported that their friends took drug or alcohol and $25 \%$ reported that their friends did not take drug or alcohol. So the finding that most of the friends of drug addict adolescents take drug or alcohol may be interpreted as common interest which has played pivotal role in forming a peer group. The findings are consistent with previous research in which McGee(20) found that peer influence had much greater impact than parental influence on adolescent drug use. Flay ${ }^{(21)}$ found that friends smoking affect adolescent initiation into smoking both directly and indirectly, whereas parental smoking influences smoking initiation only directly. Lee ${ }^{(22)}$ found that, among other variables, differential peer association mediated the effects of family structure and other variables on adolescent drinking and drug behavior.

Rate of drug taken by peers and the participants: The present study also shows that only $8.33 \%$ participants reported that their friends took drug rarely, $50 \%$ participants reported that their friends took drug occasionally and $41.67 \%$ participants reported that their friends took drug regularly. On the other hand among the drug addict adolescent, only $10 \%$ participants reported that they took drug rarely, $45 \%$ participants reported that they took drug occasionally and $45 \%$ participants reported they took drug regularly. These findings indicate that the habit of drug addict adolescent and their friends were similar, which is also an indication of peer pressure on drug addict adolescent.

Some determinates of drug used by peers and the participants: Besides these findings the study also reveals some important information. All respondents reported that they received positive and faulty information from different sources. The finding can be explained that they received most of the information about substance from dependable persons, by observing drug abusers and favorite models and by watching different movies which led to the development of drug related misconception in them. But they started to believe positive information about substances and their effects and that might have strongly influence the urge for testing substance for gratification.

Curiosity: It was found from the report of the participants themselves that, $71.67 \%$ of their friends and $66.67 \%$ of participants took drug because of curiosity. They mentioned that curiosity is one of the prime reasons to take their substance for exploring the tastes of it. The findings can be explained by the fact that if someone has strong desire to experience any risk object; he or she will be more encouraged by peers having the same type of curiosity. They become vulnerable and get easily into the trap of drug abuse friends of drug dealers. This findings is consistent with previous data on drug use that curiosity is the main reason of first drug use. 
Peer influence: The study also reveal that peer influence was strongly linked with drug dependency. $66.67 \%$ of the respondents believe that peer influence was associated with the substance abuse. Respondents took drugs under peer pressure because they felt fear of losing friends. Besides they had deficits of assertiveness that is they could not say no to their friend's invitation of substance use.

To celebrate special occasion: Many respondents clearly reported $65 \%$ of their friends and $58.33 \%$ of them took substance initially for celebrating special occasions. In Bangladesh we have better experience of this type of celebration of New Year's Eve. On the night of 31st December there is rampant use of alcohol and drug in some areas of Dhaka city.

Media: The study shows that media were linked to the substance use of the respondents. They reported that $25 \%$ of their friends and $23.33 \%$ of respondents have taken drug because of media. Respondents watch movie at satellite TV in which they observe Western and Hindi movie where heroes smoke and drink and they perform stunt activities without any problem.

Family history of drug use: According to participants, 55\% of their friends and $50 \%$ of themselves have history of drug abuse in their family. The findings can be explained by learning theories that practice of drug abuse in family members can play a strong role that can results in drug taking behavior of other members especially youngsters who are looking for role models in their life.

Family disorganization: The present study also shows that presence of a number of critical family factors among the families of the substance abusers such as conflicting parental relationship, parental divorce, extramarital relationship and too much restriction in family might have influenced to take drug. The view was found from $41.67 \%$ of participants and $33.33 \%$ of their friends.

Drug availability: $43.33 \%$ participants and $41.67 \%$ of their friends reported that drug availability was associated with initial substance use. The findings can be explained by the fact that in Bangladesh some of family permits to take some types of drug like alcohol, cannabis etc. and they also perceive it as low risk.

The second objective of the present study was to investigate of the parenting style of the fathers of the drug users. The study shows that $80 \%$ of the participant's scores were above midpoint which indicates that they perceive their fathers as rejecting. Only $20 \%$ of the addicted adolescents whose scores was below midpoint show that they do not feel parental rejection. Parental rejection can be explained by any combination of four principle expression: (a) cold and unaffectionate, the opposite of being warm and affectionate, (b) hostile and aggressive, c) indifferent and neglecting and (d) undifferentiated rejecting.

Warmth/affection: It was found that, $60 \%$ of the participants have scores below midpoint. It suggests that, the addict adolescent perceived their fathers as cold and 
uninvolving. On the other hand only $15 \%$ participants whose scores above midpoint reported their parent/fathers perceived to feel warm toward their adolescent. Participants perceive that their fathers appear emotionally cold and give little or no affection. They rarely praise their adolescents. So they got little warmth from their parents.

Hostility/aggression: It was also found from the study that most of the participants $86.67 \%$ whose score was above midpoint reported their fathers act on feeling of hostility with them, and $8.33 \%$ of the participants reported their parent did not show hostile or aggressive attitude toward them. They appear irritated, angry and impatient in facial expression, tone of voice or gesture.

Indifferent/neglect: The study shows that $68.33 \%$ of the participants whose score are above midpoint reported that their fathers are neglecting. On the other hand only $23.33 \%$ of the participants reported that their fathers do not show indifference or neglect. These parents spend little time with their child and pay little attention to the adolescent. These neglecting attitudes may lead the adolescent to be addicted or vice versa.

Undifferentiated rejection: Undifferentiated rejection refers to individual's belief that their parents do not really care about them or love them. $65 \%$ of the participants whose score are above midpoint reported that they got undifferentiated rejection from their parent and $26.67 \%$ of the respondents whose score are below midpoint reported they did not get undifferentiate rejection from their parent.

Economic status of participants: The third objective of the present study was to find the economic status of adolescent drug users. To find the economic status of adolescent drug users, the participants were divided into three groups on the basis of their family monthly income. These groups were higher economic class $(55,000 /-1,00,000)$, middle economic class $(25,000 /-50,000 /$ and lower economic class $(1,500 /-20,000 /)$. Another important finding of the study was the highest percentage of drug addict adolescent $51.65 \%$ to come from families having monthly income of taka around 15,000/which is in the perspective of Bangladesh low income. But next highest percentage of participants $28.34 \%$ come from families having income of taka 55,000 - - 1,00,000/. On the basis of these findings it may be said that drug addiction in adolescent is not limited to either high income or low income families rather they come from lowest to highest income group. Some studies supported that behavior like smoking, drinking, drug use and physical inactivity is more frequent among adolescents with a low family income ${ }^{(23-24)}$ In addition it has been found that high economic teens reported more cigarette, alcohol and drug use than low economic teens. Martin and colleagues (25) found that high socioeconomic teens more spending money engaged in greater alcohol use. It is consistent with present study findings. 
Limitation of the study: As with all studies, this study has several limitations those are enumerated as below.

- The present study was designed to investigate the relationship of friends and parenting style of the fathers of the adolescent. No comparison was made between addict and non-addict group. Further study may include a comparable group of nonaddict adolescents.

- The participants of the study were male. Therefore, nothing is known about the female drug users. Further research should include both male and female participants.

- The study was limited to Dhaka city only. So, more intensive research is needed to assess to what extent the findings of the present study can be explained to the adolescent of others area of Bangladesh.

\section{References}

1. Nutt D, LA King, W Saulsbury and C Blakemore 2007. Development of a rational scale to assess the harm of drugs of potential misuse, 360 (9566).

2. National Institute on Drug Abuse 2007. Drugs, Brains and Behavior: The science of Addiction. Washington D.C: The National Institute of Health, Retrieved. February 5, 2008 from http://www. drgabuse.gov/scienceaddiction/socioaddictio.pdf

3. Kulsudjarit K 2004. Drug problem in southeast and southeast Asia. Annals of the New York Academy of Sciences 1025(1): 446-457.

4. Burt MR 2002. Reasons to investing in adolescents. Journal of Adolescent Health, 31, 136-152.

5. Nordahl TE, Salo R and Leamon M 2003. Neuropsychological effects of chronic methamphetamine use on neurotransmitters and cognition: A review Journal of Clinical Neuroscience 15(3): 317-325.

6. Azam G 1995. Drug addiction in family life: A study of Rajshahi city. The Journal of Social Development, Institute of Social Welfare and Research, University of Dhaka 10(1).

7. Hussong AM, RE Hicks, SA Leavy, PJ Curran 2001. Specifying the relations between affect and heavy alcohol use among young adults. Journal of Abnormal Psychology 110: 449-461.

8. Kaplan HI and BJ Sadock 1998. Synopsis of Psychiatry: Behavioral Science? Clinical Psychology (8th ed., New York.

9. Barens GM, and MP Farrell 1992. Parental support and control as predictors of adolescent drinking, delinquency and related problem behaviors. Journal of Marriage and the Family 54: 763-776.

10. Coombs RH, and J Landsverk 1988. Parenting style and substance use during childhood and adolescence. Journal of Marriage and the Family 50: 473-482.

11. Li X, S Feigelman and B Stanton 2000. Perceived parental monitoring and health risk behavior among urban low income African-American children and adolescents. Journal of Adolescent Health 27: 43-48.

12. Cattarello AM, RR Clayton and CG Leukefeld 1995. Adolescent alcohol and drug abuse. Vol. 14, Washington: American Psychiatric Press. 
13. Madu SN, and MP Matla 2003. Correlations for perceived family environmental factors with substance use among adolescents in South Africa. Psychological Reports 92: 403-415.

14. Rouholamini S 2002. Formative research on familial characteristics of drug users in Iran. Yale, New Haven.

15. Lowry RL, JLKann, Collins and LJ Kolbe 1996. The effect of socio-conomic status on chronic disease risk behaviors among US adolescents. Journal of the American Medical Association, 792-797.

16. Mahmood SI and DAfrose 2010. Bangle version of Drug and alcohol use- High risk behavior assessment scale. Unpublished Manuscript, Department of Psychology, University of Dhaka.

17. Church 1994. High risk behavior assessment scale: Violence related attitude, behavior and influences among youth: A compendium of Assessment Tools (2nd ed..

18. Fatema K and D Afrose 2008. Parental child rearing pattern and adolescent adjustment. Unpublished Manuscript Department of Psychology, University of Dhaka.

19. Rohner RP 2004b. Parental acceptance-rejection/control questionnaire (PARQ). Test manual. In: Handbook for the study of parental acceptance and rejection. (4th ed., Rohner RP and A Khaleque (Eds), pp. 137-186. Storrs CT: Rohner Research Publications.

20. McGee 1992. Social class differences in parental and peer influence on adolescent drug use. Deviant Behavior 13: 349-372.

21. Flay BR, FB Hu, O Siddiqui, DL Edward, D Hedeker and J Petraitis 1994.Differential influence of parental smoking and friends smoking on adolescent initiation and escalation of smoking. Journal of Health and Behavior 35: 248-265.

22. Lee G, RL Akers and M Borg 2004. Social learning and structural factors in adolescent substance use. Western Criminology Review 5(1).

23. Green G,P West and R Ecob 1991. Like parent like child? Association between drinking and smoking behavior of parents and their children. Journal of Alcohol and Drug Dependence 745-758.

24. Lowry R, L Kann, JL Collins and LJ Kolbe 1996. The effect of socio economic status on chronic disease risk behaviors among US adolescents. Journal of the American Medical Association, 792-797.

25. Martin BA, TP McCoy, H Champion, MT Parries, RH DuRant, A Mitra and SD Rhodes 2009. The role of monthly spending money in college student drinking behaviors and their consequences. Journal of American College Health. 57: 587-596. 10.3200 JACH.57.6.587596. 